\title{
Review Paper: Behavioral, Cognitive and Neural Markers of Asperger Syndrome
}

\author{
Farnaz Faridi ${ }^{1}$, Reza Khosrowabadi ${ }^{1 *}$
}

1. Institute for Cognitive and Brain Sciences, Shahid Beheshti University, Tehran, Iran.

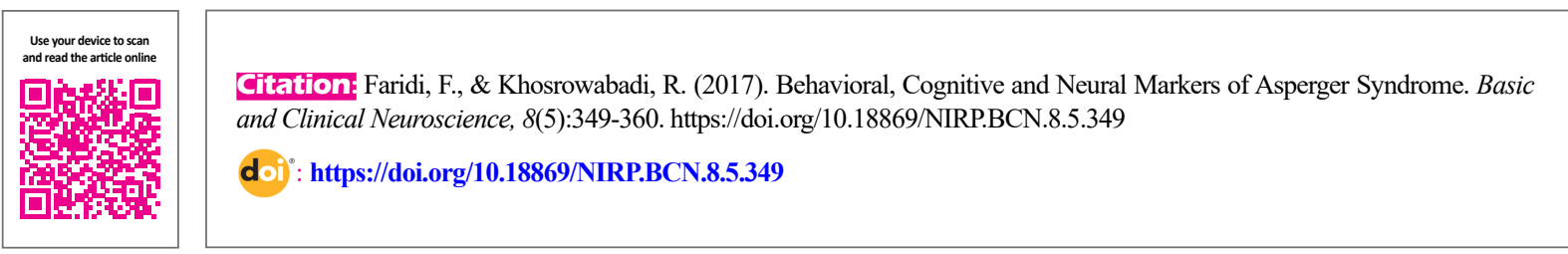

Article info:

Received: 13 Dec. 2016

First Revision: 02 Jan. 2017

Accepted: 30 Apr. 2017
Key Words:

Asperger syndrome,

Behavioral deficit,

Cognitive dysfunction,

Neurobiological marker

\begin{abstract}
A B S T RA C T
Asperger syndrome (AS) is a subtype of Autism Spectrum Disorder (ASD) characterized by major problems in social and nonverbal communication, together with limited and repetitive forms of behavior and interests. The linguistic and cognitive development in AS is preserved which help us to differentiate it from other subtypes of ASD. However, significant effects of AS on cognitive abilities and brain functions still need to be researched. Although a clear cut pathology for Asperger has not been identified yet, recent studies have largely focused on brain imaging techniques to investigate AS. In this regard, we carried out a systematic review on behavioral, cognitive, and neural markers (specifically using MRI and fMRI) studies on AS. In this paper, behavior, motor skills and language capabilities of individuals with Asperger are compared to those in healthy controls. In addition, common findings across MRI and fMRI based studies associated with behavior and cognitive disabilities are highlighted.
\end{abstract}

\section{Asperger Syndrome}

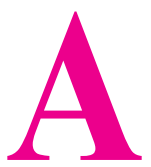

merican Psychiatric Association (APA) has recently inserted Asperger syndrome (AS) in the spectrum of Autism Spectrum Disorder (ASD). APA classification has brought many concerns for parents of children with Asperger as they thought this syndrome requires certain caring and training. In addition, experts also think that it is a premature classification because of biological differences between AS and ASD. Therefore in this review, we try to address this concern by looking at behavioral, cognitive and neural differences of patients between Asperger and autism. We would like to show whether these differences are intrinsic or a reflection of developing with different characteristics.
Asperger is defined as a neurobiological disorder that causes obvious deficiencies in social skills such as difficulty in communication and changing the routines (Iwanami et al., 2011). Gillberg defined and characterized Asperger as a social deficiency, limited interest, obligatory behavior with no verbal communication problem (Maier et al., 2002). Although Asperger disorder is considered as high functioning end of autism, there are still some important differences such as normal intelligence and nearnormal language development in AS children (Koyama \& Kurita 2008, Helles, Gillberg, Gillberg, Billstedt, 2016).

Asperger like autism could not be prevented or treated. However, recent findings indicate that early diagnosis and intervention would drastically improve the treatment process (Lopata, Thomeer Volker, \& Nida, 2006)

* Corresponding Author:

Reza Khosrowabadi, PhD

Address: Institute for Cognitive and Brain Sciences, Shahid Beheshti University, Tehran, Iran.

Tel: +98 (21) 29905404

E-mail:r_khosroabadi@sbu.ac.ir 
and directly influence the quality of patient's life. Therefore, to propose a better intervention procedure, it is crucial to look for a subtype diagnosis and consequently a specific intervention. In this regard, we believe that AS must be investigated separately. In this investigation, several co-factors could influence the procedure of diagnosis. Some of the important factors, including effects of age, gender (Asperger individuals and their parents) and Intelligence Quotient (IQ) are reviewed. Also, the effect of each factor on behavioral, chemical and brain structural changes is discussed as follows.

\subsection{Age effect}

One of the main problems in diagnosis of autism and $\mathrm{AS}$ is the late occurrence of some atypical behavioral and cognitive changes, like impairment of social communication or alteration in occurrence of puberty. These facts should be considered while proposing a compensatory learning or an intervention method to make it more effective on children or adolescents. In fact, concentration of metabolites, for instance choline, is significantly related to the age (O'Brien et al., 2010). Moreover, metabolites are good indicators of the neural density and their age dependency could also associate well with age dependency of the brain structure. In addition, extent of metabolites is also correlated with behavior and cognitive functions. Therefore, it is necessary to look at metabolic and brain structural changes while investigating the late occurrence of behavioral and cognitive functions. Studies have indicated lower choline concentration in AS individuals with increasing age (O’Brien et al., 2010).

It has also been shown that focalization of all metabolites in prefrontal lobe is higher in subjects with AS (Shamay-Tsoory et al., 2005). There are significant age related differences in terms of pattern of brain structure in Asperger subjects as compared to healthy controls. For instance, volume of cerebral hemispheres and caudate nuclei alter more by the age in AS than healthy control (McAlonan et al., 2002). In addition, maturation of the amygdala and hippocampus complex differs significantly in AS from normal people (O'Brien et al., 2010). For instance, age related increase of amygdala volume (more significant at the left side) is observed in AS people but in normal people (Murphy et al., 2012). These findings also highlight the fact that age is also another important factor for investigation of AS.

\subsection{Gender effect}

Studies commonly report that AS is observed four times more in males than females. However, profes- sionals believe in a prevalence rate of $2: 1$. In addition to prevalence rate, there are several behavioral and cognitive differences between males and females with AS. For instance, studies have shown that male AS poorly perform the emotion recognition tasks using both face and voice stimuli compared to healthy controls (Helles et al., 2016; Sucksmith, Allison, Baron-Cohen, Chakrabarti, \& Hoekstra, 2013). Regardless of diagnosis, female subjects show a better performance in face recognition compared to the males. Furthermore, male subjects in AS group have more difficulty in emotion recognition, and they do worse in the facial emotion recognition than that of voice stimuli (Golan, Baron-Cohen, Hill, 2006). Another behavior study done by Kuhnert shows association of girls prosocial behavior with their emotion understanding but no such association for boys (Kuhnert, Begeer, Fink, \& De Rosnay 2017).

Furthermore, girls show more advanced theory of mind compared to the boys in AS (Weimer, Parault Dowds, Fabricius, Schwanenflugel, \& Suh, 2017). Gender also affects the neural structure and functions. For instance, it has been reported that males with high-functioning autism and AS have a pattern of decreased grey matter density in the ventromedial regions of the temporal cortex. This fact could influence integration of visual stimuli as well as process of affective information processing (Kwon, Ow, Pedatella, Lotspeich, \& Reiss, 2007). Based on the above mentioned studies, biological sex differences should be considered as an important factor in the study of AS and we should not blindly assume that everything found in males applies to females.

\subsection{Effect of Intelligence Quotient (IQ)}

The IQ is mainly measured using two separate components, including performance and verbal levels. Studies have shown verbal and performance IQ differences between AS and normal people, although the findings are controversial (Bölte, Dziobek, \& Poustka, 2008; Kanai et al., 2012) The effect of IQ has been more studied in behavioral and cognitive level, therefore, in this section some of the related studies are reviewed.

\subsubsection{Performance IQ}

A brief report on profiling of the intelligence in AS has been presented by Spek, Scholte, Van Berckelaer-Onnes (2007). The ability was assessed by Wechsler Adult Intelligence Scale (WAIS), which is a valid indicator of IQ (Holdnack, Goldstein, Drozdick, 2011). This test is recommended as the best measurement of IQ in high functioning individuals (Bölte et al., 2008). It is reported 
that Asperger patients have poor performance in digit symbol coding and symbol search (Kanai et al., 2012). Studies have also supported weakness of AS patients in performance IQ, particularly in digit symbol coding and symbol search (Kuo, Liang, Tseng, \& Gau, 2014). Although there is evidence showing deficits of AS patients in coding but they could gain higher score in arithmetic and digit span (Koyama \& Kurita, 2008). There are also studies that have focused on reaction time and they believe AS people use significant longer reaction time and need more prompt questions to solve a task (Kaland, et al., 2002). In addition, weakness in processing speed has been reported as well (Holdnack et al., 2011). Therefore, weakness in performance IQ and speed could be good criteria to distinguish AS.

\subsubsection{Verbal IQ}

There is no robust history of language delay or of mental retardation for AS subjects. Typically, AS subjects show above average or superior verbal IQ and high scores on information and vocabulary subtests (Saulnier \& Klin, 2006). Studies have shown that AS individuals outperform in the test of fluid reasoning (Hayashi, Kato, Igarashi, \& Kashima, 2008). Despite applied use of language, rote linguistic skills such as repeating, appellation, fluency and synaptic comprehension is normal (Saulnier \& Klin, 2006; Chevallier, Noveck, Happé, \& Wilson, 2009). Therefore, AS subjects have a weak grasp of inference, understand little content, disorganized and narrative, but they show a good vocabulary and grammar skill. In AS individuals, rhythm, volume, and prosody of speech are often disturbed (Chevallier et al., 2009). In other words, AS subjects have more difficulty in brain organization of semantic and syntactic processes. Nevertheless, this deficit has been compensated by other brain regions, allowing AS individuals attain the same level of response activity as controls (Tsai et al., 2013). Therefore, IQ components should also be considered as an important factor while studying AS.

\subsection{Parents' gender effect}

AS children mostly have similar behavioral traits as their parents. For instance, during cognitive tasks a prolong latency has been reported for AS children as well as for their fathers but not their mothers. Furthermore it has also been reported that the brain responses to sound encoding stimuli are similarly abnormal in both mothers and fathers of children diagnosed with AS. However, during auditory discrimination tasks, only fathers show abnormal patterns (Jansson-Verkasalo et al., 2005). Identical abnormality of dorsolateral prefrontal cortex in both father and son with AS has also been reported (Schultz, Romanski, \& Tsatsanis, 2000). An atypical neural response to affective prosody has also been observed in children with AS and their fathers, especially over the right brain hemisphere (Korpilahti et al., 2006). Therefore, parent's gender could be considered as an important factor while studying AS.

In addition to the concern about covariates in investigating AS, it is important to understand behavioral, cognitive and neural markers of the disorder. Therefore, in this paper we try to review three important aspects of AS, including social behaviors, motor skills and language. We mainly review those studies that have used neuroimaging (MRI, fMRI) from year 1993 onward. In this review, we reported available clinical studies which seem to be relevant to our subject from PubMed, neuropsychology, autism and developmental disorder, biological psychiatry, and journal of physiology. Our search was performed using the following keywords: Asperger, Autism spectrum disorder, high functioning autism, MRI, fMRI, behavior, cognition, and neural marker. Reference list of each article was also assessed for additional citations and those relevant to Asperger studies were also included. It should be mentioned that in this paper only neuroimaging findings based on MRI and fMRI studies were reviewed and other methods such as EEG/MEG as well as non-English studies will be included in our future works.

\section{Behavioral Markers of Asperger Syndrome}

The term behavioral marker refers to a prescribed set of behaviors that could indicate some aspects of a subject's performance. Performance of a subject could be measured with different techniques. One of the commonly used techniques in this area is eye tracking because of its high reliability. Eye tracking is a process of measuring either points of gaze or motions of the eyes relative to the head (Feng \& Cai, 2016). Various theories in psychology could be assessed using this technique. For many decades it has been used for normal population, however, recent research shows a trend toward using this technique on individuals with disorders such as AS (Boraston \& Blakemore 2007).

These studies typically focus on the processing of socially salient stimuli and social interactions. So far various eye movement abnormalities, including increased errors and latencies on anti-saccadic task and impairment of pursuit have been reported (Manoach, Lindgren, Barton, 2004), for example, AS individuals mainly focus on mouth region instead of eyes (Sawyer, Williamson, Young, 2011). Moreover, AS individuals do not show 
the gaze cueing effect. This fact indicates an impairment of unconscious, but not conscious joint attention in AS (Sato, Uono, Okada, \& Toichi 2010). In addition, AS people do not show an enhancement of joint attention by fearful vs. neutral gaze which is observed in the control subjects (Uono, Sato, Toichi, 2009). Besides eye-tracking pattern, there are several cognitive abilities affected in AS. Some of the important impaired abilities are explained in the following.

AS is also characterized by stereotypic and obsessional behavior and abnormalities in socioemotional and communicative behavior (McAlonan et al., 2002). Some AS patients are known to commit offences and more likely violent offences against strangers (Tantam \& Girgis, 2008). Moreover, a lower score on the Friendship Questionnaire (FQ) has been reported in AS subjects (BaronCohen \& Wheelwright, 2003). Lack of sense of humor has also been reported, although anecdotal and prenatal reports provide some evidence to the contrary (Lyons \& Fitzgerald 2004). Furthermore, inability to laugh at themselves (gelotophilia), but enjoy laughing at others (katagelasticism) has also been reported in AS group (Kaplar, 2011). According to Helles findings, there is a characteristic discrepancy between AS pure (no current psychiatry comorbidity) and AS plus (AS and one other current disorder). AS pure shows indifferent and detached behavior while AS plus are worrying, fearful, shy and fatigable (Helles et al., 2016).

\subsection{Irregularity of movement in Asperger syndrome}

Motor abnormality includes variety of impairments; inability to execute a sequence of actions, atypical eye movement and deficiencies in motor learning (Setoh, Marschik, Einspieler, \& Esposito, 2017). There are several studies examining movement in AS patients, presenting abnormalities in motion performance (Price, Edgell, Kerns, 2012). In addition, different visual sensitivity to the movement and postural responsivity to the optic flow, correlate with motor skills (Price, Shiffrar, Kerns, 2012). There is also significant impairment of movement performance as well as proprioceptive and vestibular processing in AS (Siaperas et al., 2011). Furthermore, AS individuals show deficit in explicit motor-sequence learning that could be related to the left hemisphere dysfunction (Izadi-Najafabadi, Nejati, Mirzakhany-Araghi, \& Pashazadeh-Azari, 2013). Explicit learning of right and left hand movement is impaired in AS. However, despite the impairment of explicit learning (Watanabe, Ikeda, Miyao, 2010), the implicit learning of both hands maintains intact. Attractively, a right hand preference in implicit motor learning is observed in AS individuals due to left striatal system abnormality (Izadi-Najafabadi et al., 2013).

\section{Cognitive Markers of Asperger Syndrome}

AS adults have distinct pattern of cognition from healthy control (Bucaille et al., 2016). Several areas of the cognitive style and functions are disrupted in AS such as social skills (Myles \& Simpson, 2001), joint attention (Tanguay, Robertson Derrick, 1998), central coherence (Jolliffe \& Baron-Cohen, 1999), executive functioning (Semrud-Clikeman, Walkowiak, Wilkinson, \& Butcher, 2010) and implicit social cognition (Lugnegard, Unenge Hallerbäck, Hjärthag, \& Gillberg, 2013). There are several tasks, which could be used to measure cognitive abilities in AS subjects such as Wechsler intelligence scale, Neuropsychological Assessment (NEPSY), reading the mind in the eyes, Multifaceted Empathy Test (MET), folk psychology, folk physic test, reading the mind in the voice, and embedded figure test. Therefore, some of the related studies are reviewed in the following.

It has been reported that AS patients show decreased pointing accuracy, timing accuracy and postural stability (Gowen \& Miall, 2005). They recall fewer memories, which are often rated as known. They show fewer social identities and more abstract and trait-linked identities (Tanweer, Rathbone, Souchay, 2010). In addition, AS individuals have significant impairments on test of visual memory and on executive functioning, flexibility and generativity (Ambery, Russell, Perry, Morris, \& Murphy, 2006). In addition, AS individuals experience difficulties with extra-dimensional/conceptual shifts (between categories or rules) (Brady et al., 2013). Interestingly, they do not differ from controls in their judgments of causality or blame judgment in relation with non-mentalistic factors. In contrast, they are more sensitive to mentalistic considerations in their attributions of blame. They make greater differentiation between intentional and unintentional actions as compare to controls. They also better differentiate between actions with likely protagonists believed versus unlikely ones that lead to negative consequences (Channon, Lagnado Fitzpatrick, Drury, \& Taylor, 2011).

In general, AS children respond faster and more accurately to expression of happy faces than controls (Wong, Beidel Sarver, \& Sims, 2012). However AS and control do not differ in their emotional expression and responses to facial stimuli (Doody \& Bull, 2012). Moreover, AS individuals perform as accurate as controls at matching fear body postures, but less accurate than controls in verbally identifying the same stimuli (Doody \& Bull, 2012). Moreover, individuals with AS may have an impaired 
response to change their environment (Brosnan, TurnerCobb, Munro-Naan, \& Jessop, 2009). They also fail to show interaction effect (Shamay-Tsoory, Gev, AharonPeretz, \& Adler, 2010). The AS subjects are impaired in folk psychology but superior in folk physics (BaronCohen, Wheelwright, Spong, Scahill, \& Lawson, 2001). Another key feature of AS is lack of theory of mind (Nieminen-Von et al., 2003, Frith, 2004). Moreover, the cognitive planning is also weaker in AS individuals (Ashley Jones Reno, 2013). However, they outperform on the fluid reasoning test (Hayashi et al., 2008). It is also interesting that AS subjects are impaired in cognitive empathy, but they do not differ from controls in emotional empathy (Dziobek et al., 2007). Similarly, O'Brien reported the intactness of affective empathy and recognition of negative emotions in AS (O'Brien et al., 2010).

\section{1. Language domain in Asperger syndrome}

There is no difference between High Functioning Autism (HFA) and AS in verbal skills but their history of language acquisition is different (Bennett et al., 2007). History of language acquisition and the time at which language is acquired, is crucial for configuration of AS phenotype (McAlonan et al., 2009). AS individuals show no problem in literal semantic processing, which is a rule-based task. However, they have deficit in violating processing, like metaphors (Gold \& Faust, 2012). They make more mistakes in appropriate metaphoric sentences than in scrambled metaphors. These findings indicate intact automatic metaphor processing in AS (Hermann et al., 2013). In addition to metaphor comprehension (Gold, Faust, Goldstein, 2010), AS individuals have difficulty in social interactions and understanding sarcasm (Smucker, 2011) which are related to less activity of right brain hemisphere in AS group.

In contrast, some studies attribute difficulties in the comprehension of metaphors in AS to differences in linguistic information processing (Gold et al., 2010). Problems in audio speech perception has been reported (Saalasti et al., 2011). Similar findings have been observed in visual articulation as well. This may relate well with the difficulties in face to face communication in AS individuals (Saalasti, Tiippana, Kätsyri, \& Sams, 2011). Moreover, spreading grammatical prosody has also been indicated in AS (Chevallier et al., 2009). It is interesting that AS individuals are unable to talk about their own emotions but they can write about their lives (Frith, 2004). Fortunately, despite the changes in organization of the brain for semantic and syntactic processing in AS group, the other brain mechanisms (top-down regulation) can compensate the deficits and allow AS to attain the same level of response and activation as healthy controls (Tsai et al., 2013).

In other words, the above mentioned behavioral and cognitive dysfunctions have neurobiological basis that requires to be reviewed as well. Since the brain is the center of cognitive functions, a comprehensive review requires covering findings on structural and functional changes of the brain in AS subjects. Anatomical structure of the brain is normally investigated by Magnetic Resonance Imaging (MRI) (Berthier, Bayes, Tolosa, 1993). MRI technology could also be used to measure brain functions by tracking the hemodynamic response (BOLD signal) in response to stimuli. Therefore, this technique has largely been used to track anatomical and functional changes of the brain. The following section provides a review on recent findings on structural and functional differences in AS individuals.

\section{Neurobiological Basis of Asperger Syndrome}

AS causes some chemical, structural and functional abnormalities in the brain which are discussed in following.

\subsection{Chemical markers}

There are several neurotransmitters responsible for dampening or facilitating cellular activities in the brain. Studies have shown that concentration of neurotransmitters are different in AS and it influences the brain functioning pattern. A higher level of N-acetyl aspartate/ choline (NAA/Cho) level in AS has been found at the right anterior cingulate (Oner, Devrimci-Ozguven et al. 2007). In addition, [18F] F-Dopa influx(k) increase in the striatum, putamen ,caudate nucleus and frontal cortex has been reported (Nieminen-von Wendt et al., 2004). This clearly indicates that dopaminergic system is largely affected in AS.

It should be mentioned that association between changes in neurotransmitter levels and cognitive behavior has also been explored in AS. For instance, changes in level of NAA/Cho are positively correlated with the obsessive compulsive scale that is affected in AS. Moreover, changes in modulation of serotonin in the brain by acute tryptophan depletion could lead to deviation in the processing of emotional faces in male AS compared to controls (Daly et al., 2008). In addition, intranasal administration of the neuropeptide oxytocin could improve performance of the AS subjects in a facial emotion recognition task (Domes, Kumbier, Heinrichs, \& Herpertz 2013). Similarly, Domes group suggested that applying oxytocin may improve affective speech comprehension 
and increase eye gaze, emotion recognition as well as social interaction (Domes et al., 2013). Beside the neurochemical differences in AS individuals, there are some brain structural changes that are listed in the following.

\section{2. Brain structural changes}

The spread and heterogeneity of the neuroimaging findings about AS suggest that it is a widely distributed disorder affecting both grey and white matters. Volume of grey and white matter of some brain regions are different in AS. Neuroimaging studies have indicated lower grey matter volumes in the bilateral amygdala, hippocampus gyrus, prefrontal lobe, medial frontal gyrus, left occipital gyrus, right cerebellum, limbic striatal, bilateral caudate, left thalamus, putamen and precuneus as compared to healthy controls (McAlonan et al., 2008; Ameis et al., 2011, Semrud-Clikeman \& Fine, 2011).

In addition, greater grey matter volumes have also been observed in AS at the bilateral inferior parietal lobule and the left fusiform gyrus. Moreover, a higher volume of white matter has been reported around the basal ganglia, left parietal lobe, but a lower white matter volume has also been observed at the right frontal region and corpus callosum (McAlonan et al., 2009). In addition to abnormalities in white and grey matter, the anterior posterior diameters of the mesencephalon are significantly shorter in AS (Nieminen-von Wendt et al., 2002).

In terms of structural organization of the brain, AS patients have lower fractional anisotropy in the short intracerebellar fibers and right superior cerebellar peduncle. This has been reported to be largely bilateral and includes white matter in the internal capsule, frontal, temporal, parietal and occipital lobe, cingulum and corpus callosum (Bloemen et al., 2010). Furthermore, abnormality in volumes of hippocampus, amygdala and Anterior Cingulate Cortex (ACC) has been reported. The brain anatomical and structural abnormalities cause the cognitive deficits in AS. For instance, the abnormalities at the ACC, amygdala and hippocampal regions in AS are likely the main contributor of their difficulty with modulating of emotional reactivity (Semrud-Clikeman, Fine, Bledsoe, \& Zhu, 2013). Moreover, the localized cerebral abnormalities in AS discharge adaptive social behavior (Catani et al., 2008). In addition, volumetric exes in the Asperger group at the inferior parietal lobule is linked to synesthesia (Welchew et al., 2005) and dysfunction within frontostriatal and cerebellar motor circuits also reflect chaotic movement (Nayate, Bradshaw, Rinehart, 2005). Furthermore, association between abnormalities and size of some particles in the brain has been observed. For instance, measures of entropy and uniformity have been reported to be related to the volume of the caudate nuclei. In terms of global features, average of the grey matter volume is related to the size of the cerebellar vermis (Radulescu et al., 2012) and there is no positive relationship between the total brain volume and size of thalamus in AS group (Hardan et al., 2007). In addition to brain structural differences in AS individuals compared to healthy controls, lesions could also be found mainly in occipital lobe in AS group, on the areas responsible for visual/spatial reasoning (Semrud-Clikeman \& Fine, 2011).

\section{3. Brain functional changes}

Functional studies with the help of pattern recognition techniques are converging on the hypothesis that AS is associated with atypical decreased functional connectivity between nodes in the default mode network (Funai, Bharadwaj, Grissom, 2007) and executive control network (Han \& Chan, 2017). Functional abnormalities exist in cerebella, frontal and temporal lobes, and limbic system (Sugihara, Ouchi. Nakamura, Sekine, \& Mori 2007). In addition, significant abnormality in the functional integration of amygdala and parahippocampal gyrus have also been observed (Welchew et al., 2005). Interestingly, neuroimaging patterns of AS individuals are not affected by stimuli type (static and dynamic faces) (Horlin et al., 2013). For instance, story task and cartoon task activate the same region of brain (medial prefrontal region) (Castelli, 2002). Additionally, main emotions, manifested by face, can activate fusiform and extra striates (Deeley et al., 2007).

Despite the believe that neurobiological underpinning in AS and High Functioning Autism (HFA) are not separated, recent studies indicate that orbitofrontal functionality compromises in HFA but integrates in AS (May et al., 2010). However, similarities are also observed in both groups for instance in striate and extra-striate areas (Bókkon, Salari, Scholkmann, Dai, \& Grass, 2013). After all, the most dominant aspects of diagnosis of AS are behavior, then language and movement. Therefore, in the following sections, we will review articles published on the above mentioned domains in AS.

\section{Comorbidity of Asperger Syndrome and Psychiatric Disorders}

Many AS individuals develop secondary psychiatric disorders in adolescence and adulthood. This could be because of genetic, psychiatric family history, and neurological diseases in autistic spectrum disorders. The most common comorbidity include Attention Deficit 
and Hyperactivity Disorder (ADHD), depression, or both (Gillberg, Helles, Billstedt, \& Gillberg, 2015). They more likely to have relatives with depression, schizophrenia, and broader autistic phenotype. Moreover, AS seems to be more prevalent in adults with ADHD. Along with above mentioned disease, bipolar disorder in AS is frequently observed (Vannucchi et al., 2014).

Studies have also shown that persons with frontotemporal lobe degeneration, like those with maladaptive behavior, may suffer from subclinical AS, too. Gender dysphoria (Shumer, Reisner, Edwards-Leeper, \& Tishelman, 2016) and NLD (Hagberg, Billstedt, Nydén, \& Gillberg, 2015) as well as Post-Traumatic Stress Disorder (PTSD) (Ipci, Inci, Akyol Ardiç, \& Ercan, 2017) have also been reported to be comorbid with AS. These studies report coincidence of Asperger and other disorders. Therefore, investigation of these comorbidities and brain structural similarities among AS people and individuals with ADHD, schizophrenia, depression and anxiety are also recommended for future studies.

In summary, several findings on abnormalities of behavior, cognition and brain structure and functions in AS were discussed. According to previous studies, the most apparent characteristics of AS individuals are the stereotypic and obsessive behavior as well as abnormalities in socioemotional and communicative behavior. Furthermore, they show more irregularities in motor development. Moreover, history of language acquisition is also important. In other words, better understanding of behavioral and cognitive abnormalities requires a better knowledge of neural alteration in AS. In general, studies point to structural abnormalities in AS such as decrease in grey matter at temporal cortex, bilateral amygdala, hippocampus gyrus, prefrontal lobe, medial frontal gyrus, left occipital gyrus, right cerebellum, limbic striatal, bilateral caudate, left thalamus, putamen and precuneus. There are also functional abnormalities in cerebellum, frontal, temporal lobes, and limbic system.

In addition, male AS are considerably more than females and since functional abnormalities of AS children are similar to their fathers, it is also advisable to look at parent/ gender effect as well. The findings could help on early diagnosis and proposing an earlier intervention program.

\section{Acknowledgments}

This research did not receive any specific grant from funding agencies in the public, commercial, or not-forprofit sectors.

\section{Conflict of Interest}

All authors certify that this manuscript has neither been published in whole nor in part nor being considered for publication elsewhere. The authors have no conflicts of interest to declare.

\section{References}

Ambery, F. Z., Russell, A. J., Perry, K., Morris, R., \& Murphy, D. G. M. (2006). Neuropsychological functioning in adults with Asperger syndrome. Autism, 10(6), 551-564. doi: $10.1177 / 1362361306068507$

Ameis, S. H., Fan, J., Rockel, C., Voineskos, A. N., Lobaugh, N J., Soorya, L., et al. (2011). Impaired structural connectivity of socio-emotional circuits in autism spectrum disorders: A diffusion tensor imaging study. PLoS ONE, 6(11), e28044. doi: 10.1371/ journal.pone.0028044

Ashley Jones Reno, P. M. (2013). Executive dysfunction in autism and asperger's disorder: A meta-analytic review of cognitive planning [PhD thesis]. Dayton: Wright State University.

Baron-Cohen, S., \& Wheelwright, S. (2003). The Friendship Questionnaire: An investigation of adults with Asperger syndrome or high-functioning autism, and normal sex differences. Journal of Autism and Developmental Disorders, 33(5), 509-517. PMID: 14594330

Baron-Cohen, S., Wheelwright, S., Spong, A., Scahill, V., \& Lawson, J. (2001). Are intuitive physics and intuitive psychology independent? A test with children with Asperger syndrome. Journal of Developmental and Learning Disorders, 5(1), 47-78.

Bennett, T., Szatmari, P., Bryson, S., Volden, J., Zwaigenbaum L., Vaccarella, L., et al. (2007). Differentiating autism and Asperger syndrome on the basis of language delay or impairment. Journal of Autism and Developmental Disorders, 38(4), 616-625. doi: 10.1007/s10803-007-0428-7

Berthier, M. L., Bayes, A., \& Tolosa, E. S. (1993). Magnetic resonance imaging in patients with concurrent Tourette's disorder and Asperger's syndrome. Journal of the American Academy of Child \& Adolescent Psychiatry, 32(3), 633-639. doi: 10.1097/00004583-199305000-00021

Bloemen, O. J. N., Deeley, Q., Sundram, F., Daly, E. M., Barker G. J., Jones, D. K., et al. (2010). White matter integrity in Asperger syndrome: A preliminary diffusion tensor magnetic resonance imaging study in adults. Autism Research, 3(5), 203-213. doi: 10.1002/aur.146

Bókkon, I., Salari, V., Scholkmann, F., Dai, J., \& Grass, F. (2013) Interdisciplinary implications on autism, savantism, Asperger syndrome and the biophysical picture representation: Thinking in pictures. Cognitive Systems Research, 22-23, 67-77. doi: 10.1016/j.cogsys.2012.05.002

Bölte, S., Dziobek, I., \& Poustka, F. (2008). Brief report: The level and nature of autistic intelligence revisited. Journal of Autism and Developmental Disorders, 39(4), 678-682. doi: 10.1007/s10803-0080667-2 
Boraston, Z., \& Blakemore, S. J. (2007). The application of eyetracking technology in the study of autism. The Journal of Physiology, 581(3), 893-898. doi: 10.1113/jphysiol.2007.133587

Brady, D. I., Schwean, V. L., Saklofske, D. H., Mc Crimmon, A. W., Montgomery J. M. \& Thorne, K. J. (2013). Conceptual and perceptual set-shifting executive abilities in young adults with Asperger's syndrome. Research in Autism Spectrum Disorders 7(12), 1631-1637. doi: 10.1016/j.rasd.2013.09.009

Brosnan, M., Turner-Cobb, J., Munro-Naan, Z., \& Jessop, D. (2009). Absence of a normal Cortisol Awakening Response (CAR) in adolescent males with Asperger syndrome (AS) Psychoneuroendocrinology, 34(7), 1095-100. doi: 10.1016/j.psyneuen.2009.02.011

Bucaille, A., Grandgeorge, M., Degrez, C., Mallégol, C., Cam, P., Botbol, M., \& Planche, P. (2016). Cognitive profile in adults with Asperger syndrome using WAIS-IV: Comparison to typical adults. Research in Autism Spectrum Disorders, 21, 1-9. doi 10.1016/j.rasd.2015.09.001

Castelli, F. (2002). Autism, Asperger syndrome and brain mechanisms for the attribution of mental states to animated shapes. Brain, 125(8), 1839-1849. doi: 10.1093/brain/awf189

Catani, M., Jones, D. K., Daly, E., Embiricos, N., Deeley, Q. Pugliese, L., et al. (2008). Altered cerebellar feedback projections in Asperger syndrome. NeuroImage, 41(4), 1184-1191. doi: 10.1016/j.neuroimage.2008.03.041

Channon, S., Lagnado, D., Fitzpatrick, S., Drury, H., \& Taylor, I (2011). Judgments of cause and blame: Sensitivity to intentionality in Asperger's syndrome. Journal of Autism and Developmental Disorders, 41(11), 1534-1542. doi: 10.1007/s10803-011-1180-6

Chevallier, C., Noveck, I., Happé, F., \& Wilson, D. (2009). From acoustics to grammar: Perceiving and interpreting grammatical prosody in adolescents with Asperger syndrome. Research in Autism Spectrum Disorders, 3(2), 502-516. doi: 10.1016/j. rasd.2008.10.004

Daly, E., Deeley, Q., Surguladze, S., Phillips, M., Craig, M., \& Murphy, D. (2008). Effect of serotinin on processing of emotional faces in Asperger's syndrome. fMRI and acute tryptophan depletion. Paper presented at The International Meeting for Autism Research, Londen, England, 15-17 May 2008.

Deeley, Q., Daly, E. M., Surguladze, S., Page, L., Toal, F., Robertson, D., et al. (2007). An event related functional magnetic resonance imaging study of facial emotion processing in Asperger syndrome. Biological Psychiatry, 62(3), 207-217. doi: 10.1016/j. biopsych.2006.09.037

Domes, G., Kumbier, E., Heinrichs, M., \& Herpertz, S. C. (2013) Oxytocin promotes facial emotion recognition and amygdala reactivity in adults with Asperger syndrome. Neuropsychopharmacology, 39(3), 698-706. doi: 10.1038/npp.2013.254

Doody, J. P., \& Bull, P. (2012). Evidence for impaired verbal identification but intact nonverbal recognition of fearful body postures in Asperger's syndrome. Journal of Autism and Developmental Disorders, 43(7), 1652-1661. doi: 10.1007/s10803-012$1715-5$

Dziobek, I., Rogers, K., Fleck, S., Bahnemann, M., Heekeren, H R., Wolf, O. T., \& Convit, A. (2007). Dissociation of cognitive and emotional empathy in adults with Asperger syndrome using the Multifaceted Empathy Test (MET). Journal of Autism and Developmental Disorders, 38(3), 464-473. doi: 10.1007/s10803-007-0486-x
Feng, Y., \& Cai, Y. (2016). A gaze tracking system for children with autism spectrum disorders. Gaming Media and Social Effects, 137-145. doi: 10.1007/978-981-10-0861-0_10

Frith, U. (2004). Emanuel Miller lecture: Confusions and controversies about Asperger syndrome. Journal of Child Psychology and Psychiatry, 45(4), 672-686. doi: 10.1111/j.1469-7610.2004.00262.x

Funai, A., Bharadwaj, H., Grissom, W (2007). Final report: Improved discrimination of Asperger patients using fMRI and machine learning [Internet]. Retrived from: http://citeseerx.ist.psu.edu/viewdoc/download?doi= 10.1.1.135.6789\&rep=rep1\&type $=$ pdf

Gillberg, I. C., Helles, A., Billstedt, E., \& Gillberg, C. (2015). Boys with Aspergersyndrome grow up: Psychiatric and neurodevelopmental disorders 20 years after initial diagnosis. Journal of Autism and Developmental Disorders, 46(1), 74-82. doi: 10.1007/ s10803-015-2544-0

Golan, O., Baron-Cohen, S., \& Hill, J. (2006). The Cambridge Mindreading (CAM) face-voice battery: Testing complex emotion recognition in adults with and without Asperger syndrome. Journal of Autism and Developmental Disorders, 36(2), 169-183. doi: $10.1007 /$ s10803-005-0057-y

Gold, R., \& Faust, M. (2012). Metaphor comprehension in persons with Asperger's syndrome: Systemized versus non-systemized semantic processing. Metaphor and Symbol, 27(1), 55-69. doi: $10.1080 / 10926488.2012 .638826$

Gold, R., Faust, M., \& Goldstein, A. (2010). Semantic integration during metaphor comprehension in Asperger syndrome. Brain and Language, 113(3), 124-134. doi: 10.1016/j.bandl.2010.03.002

Gowen, E., \& Miall, R. C. (2005). Behavioural aspects of cerebellar function in adults with Asperger syndrome. The Cerebellum 4(4), 279-289. doi: 10.1080/14734220500355332

Hagberg, B., Billstedt, E., Nydén, A., \& Gillberg, C. (2014). Asperger syndrome and nonverbal learning difficulties in adult males: self- and parent-reported autism, attention and executive problems. European Child E Adolescent Psychiatry, 24(8), 969-977. doi: 10.1007/s00787-014-0646-4

Han, Y. M. Y., \& Chan, A. S. (2017). Disordered cortical connectivity underlies the executive function deficits in children with autism spectrum disorders. Research in Developmental Disabilities, 61, 19-31. doi: 10.1016/j.ridd.2016.12.010

Hardan, A. Y., Girgis, R. R., Adams, J., Gilbert, A. R., Melhem, N. M., Keshavan, M. S., et al. (2007). Brief report: abnormal association between the thalamus and brain size in Asperger's disorder. Journal of Autism and Developmental Disorders, 38(2), 390-394. doi: 10.1007/s10803-007-0385-1

Hayashi, M., Kato, M., Igarashi, K., \& Kashima, H. (2008). Superior fluid intelligence in children with Asperger's disorder. Brain and Cognition, 66(3), 306-310. doi: 10.1016/j.bandc.2007.09.008

Helles, A., Gillberg, C. I., Gillberg, C., Billstedt, E. (2016). Asperger syndrome in males over two decades: Stability and predictors of diagnosis. Journal of Child Psychology and Psychiatry, 56(6), 711-8. doi: 10.1111 /jcpp.12334

Hermann, I., Haser, V., Van Elst, L. T., Ebert, D., Müller-Feldmeth, D., Riedel, A., \& Konieczny, L. (2013). Automatic metaphor processing in adults with Asperger syndrome: A metaphor interference effect task. European Archives of Psychiatry and Clinical Neuroscience, 263(S2), 177-187. doi: 10.1007/s00406-013-04539 
Holdnack, J., Goldstein, G., \& Drozdick, L. (2011). Social perception and WAIS-IV performance in adolescents and adults diagnosed with Asperger's syndrome and autism. Assessment, 18(2), 192-200. doi: 10.1177/1073191110394771

Horlin, C., Falkmer, M., Fitzgerald, P., Leung, D., Ordqvist, A., \& Falkmer, T. (2013). The influence of static versus naturalistic stimuli on face processing in children with and without Asperger syndrome or high-functioning autism. Research in Autism Spectrum Disorders, 7(12), 1617-1624. doi: 10.1016/j. rasd.2013.09.012

Ipci, M., Inci, S. B., Akyol Ardiç, Ü., \& Ercan, E. S. (2017). A case of Asperger syndrome with comorbidity of posttraumatic stress disorder and selective mutism: Significant remission with the combination of aripiprazole and eye movement desensitization and reprocessing. Journal of Clinical Psychopharmacology, 37(1), 109-110. doi: 10.1097/jcp.0000000000000627

Iwanami, A., Okajima, Y., Ota, H., Tani, M., Yamada, T., Hashimoro, R., et al. (2011). Task dependent prefrontal dysfunction in persons with Asperger's disorder investigated with multichannel near-infrared spectroscopy. Research in Autism Spectrum Disorders 5(3), 1187-93. doi: 10.1016/j.rasd.2011.01.005

Izadi-Najafabadi, S., Mirzakhani-Araghi, N., Nejati, V., Pashazadeh-Azari, Z., \& Zahedi-Barough, A. (2013). Right hand preference in implicit motor learning in children with high-functioning autism and Asperger syndrome. Iranian Rehabilitation Journal, 11(Special Issue), 70-80.

Jansson-Verkasalo, E., Kujala, T., Jussila, K., Mattila, M. L., Moilanen, I., Näätänen, R., et al. (2005). Similarities in the phenotype of the auditory neural substrate in children with Asperger syndrome and their parents. European Journal of Neuroscience, 22(4), 986-990. doi: 10.1111/j.1460-9568.2005.04216.x

Jolliffe, T., \& Baron-Cohen, S. (1999). A test of central coherence theory: linguistic processing in high-functioning adults with autism or Asperger syndrome: is local coherence impaired? Cognition, 71(2), 149-185. doi: 10.1016/s0010-0277(99)00022-0

Kaland, N., Møller-Nielsen, A., Callesen, K., Mortensen, E. L., Gottlieb, D., \& Smith, L. (2002). A newadvanced'test of theory of mind: evidence from children and adolescents with Asperger syndrome. Journal of Child Psychology and Psychiatry, 43(4), 517528. doi: $10.1111 / 1469-7610.00042$

Kanai, C., Tani, M., Hashimoto, R., Yamada, T., Ota, H., Watanabe, H., et al. (2012). Cognitive profiles of adults with Asperger's disorder, high-functioning autism, and pervasive developmental disorder not otherwise specified based on the WAIS-III. Research in Autism Spectrum Disorders, 6(1), 58-64. doi: 10.1016/j. rasd.2011.09.004

Kaplar, J. E. (2011). Humor as an educational and therapeutic tool: Living with Asperger's syndrome in a land of neurotypicals [Internet]. Retrived from: https://www.scribd.com/ document/20229841/Humor-as-an-Educational-and-Therapeutic-Tool-Living-with-Asperger-s-Syndrome-in-a-Land-Neuro-Typicals

Korpilahti, P., Jansson-Verkasalo, E., Mattila, M. L., Kuusikko, S., Suominen, K., Rytky, S., et al. (2006). Processing of affective speech prosody is impaired in Asperger syndrome. Journal of Autism and Developmental Disorders, 37(8), 1539-1549. doi: 10.1007/s10803-006-0271-2

Koyama, T., \& Kurita, H. (2008). Cognitive profile difference between normally intelligent children with Asperger's disorder and those with pervasive developmental disorder not otherwise specified. Psychiatry and Clinical Neurosciences, 62(6), 691-696. doi: 10.1111/j.1440-1819.2008.01871.x

Kuhnert, R. L., Begeer, S., Fink, E., \& De Rosnay, M. (2017). Gender-differentiated effects of theory of mind, emotion understanding, and social preference on prosocial behavior development: A longitudinal study. Journal of Experimental Child Psychology, 154, 13-27. doi: 10.1016/j.jecp.2016.10.001

Kuo, C. C., Liang, K. C., Tseng C. C., \& Gau S. S. F. (2014). Comparison of the cognitive profiles and social adjustment between mathematically and scientifically talented students and students with Asperger's syndrome. Research in Autism Spectrum Disorders, 8(7), 838-850. doi: 10.1016/j.rasd.2014.04.004

Kwon, H., Ow, A. W., Pedatella, K. E., Lotspeich, L. J., \& Reiss, A L. (2007). Voxel-based morphometry elucidates structural neuroanatomy of high-functioning autism and Asperger syndrome Developmental Medicine \& Child Neurology, 46(11), 760-764. doi: 10.1111/j.1469-8749.2004.tb00996.x

Lopata, C., Thomeer, M. L., Volker, M. A., \& Nida, R. E. (2006) Effectiveness of acognitive-behavioral treatment on the social behaviors of children with Asperger disorder. Focus on Autism and Other Developmental Disabilities, 21(4), 237-244. doi: $10.1177 / 10883576060210040501$

Lugnegård, T., Unenge Hallerbäck, M., Hjärthag, F., \& Gillberg C. (2013). Social cognition impairments in Asperger syndrome and schizophrenia. Schizophrenia Research, 143(2-3), 277-284. doi: 10.1016/j.schres.2012.12.001

Lyons, V., \& Fitzgerald, M. (2004). Humor in autism and Asperger syndrome. Journal of Autism and Developmental Disorders, 34(5), 521-531. doi: 10.1007/s10803-004-2547-8

Maier, R. F., Obladen, M., Müller-Hansen, I., Kattner, E., Merz, U., Arlettaz, R., et al. (2002). Early treatment with erythropoietin $\beta$ ameliorates anemia and reduces transfusion requirements in infants with birth weights below $1000 \mathrm{~g}$. The Journal of Pediatrics, 141(1), 8-15. doi: 10.1067/mpd.2002.124309

Manoach, D., Lindgren, K., Barton, J. (2004). Deficient saccadic inhibition in Asperger's disorder and the social-emotional processing disorder. Journal of Neurology, Neurosurgery \& Psychiatry, 75(12), 1719-1726. doi: 10.1136/jnnp.2003.025981

May, T., Brewer, W. J., Rinehart, N. J., Enticott, P. G., Brereton A. V., \& Tonge, B. J. (2010). Differential olfactory identification in children with autism and Asperger's disorder: A comparative and longitudinal study. Journal of Autism and Developmental Disorders, 41(7), 837-847. doi: 10.1007/s10803-010-1101-0

McAlonan, G., Cheung, C., Cheung, V., Wong, N., Suckling, J., \& Chua, S. (2009). Differential effects on white-matter systems in high-functioning autism and Asperger's syndrome. Psychological Medicine, 39(11), 1885-93. doi: 10.1017/s0033291709005728

McAlonan, G. M., Daly, E., Kumari, V., Critchley, H. D., Van Amelsvoort, T., Suckling, J., et al. (2002). Brain anatomy and sensorimotor gating in Asperger's syndrome. Brain, 125(7), 15941606. doi: 10.1093 /brain/awf150

McAlonan, G. M., Suckling, J., Wong, N., Cheung, V., Lienenkaemper, N., Cheung, C., et al. (2008). Distinct patterns of grey matter abnormality in high-functioning autism and Asperger's syndrome. Journal of Child Psychology and Psychiatry, 49(12), 1287-1295. doi: 10.1111/j.1469-7610.2008.01933.x

Murphy, C. M., Deeley, Q., Daly, E., Ecker, C., O’Brien, F., Hallahan, B., et al. (2012). Anatomy and aging of the amygdala and 
hippocampus in autism spectrum disorder: An in vivo magnetic resonance imaging study of Asperger syndrome. Autism Research, 5(1), 3-12. doi: 10.1002/aur.227

Myles, B. S., \& Simpson, R. L. (2001). Understanding the hidden curriculum an essential social skill for children and youth with Asperger syndrome. Intervention in School and Clinic, 36(5), 279286. doi: $10.1177 / 105345120103600504$

Nayate, A., Bradshaw J. L., \& Rinehart N. J. (2005). Autism and Asperger's disorder: Are they movement disorders involving the cerebellum and/or basal ganglia? Brain Research Bulletin, 67(4), 327-334. doi: 10.1016/j.brainresbull.2005.07.011

Nieminen-von Wendt, T., Metsähonkala, L., Kulomäki, T., Aalto, S., Autti, T., Vanhala, R., \& von Wendt, L. (2003). Changes in cerebral blood flow in Asperger syndrome during theory of mind tasks presented by the auditory route. European Child $\mathcal{E}$ Adolescent Psychiatry, 12(4), 178-189. doi: 10.1007/s00787-0030337-z

Nieminen-von Wendt, T., Salonen, O., Vanhala, R., Kulomäki, T., Von Wendt, L., \& Autti, T. (2002). A quantitative controlled MRI study of the brain in 28 persons with Asperger syndrome. International Journal of Circumpolar Health, 61. doi: 10.3402/ijch. v61i0.17500

Nieminen-von Wendt, T. S., Metsähonkala, L., Kulomäki, T. A., Aalto, S., Autti, T. H., Vanhala, R., et al. (2004). Increased presynaptic dopamine function in Asperger syndrome. NeuroReport, 15(5), 757-760. doi: 10.1097/00001756-200404090-00003

O’Brien, F. M., Page, L., O'Gorman, R. L., Bolton, P., Sharma, A., Baird, G., et al. (2010). Maturation of limbic regions in Asperger syndrome: A preliminary study using proton magnetic resonance spectroscopy and structural magnetic resonance imaging. Psychiatry Research: Neuroimaging, 184(2), 77-85. doi: 10.1016/j. pscychresns.2010.08.007

Oberman, L., Eldaief, M., Fecteau, S., Ifert-Miller, F., Tormos, J. M., \& Pascual-Leone, A. (2012). Abnormal modulation of corticospinal excitability in adults with Asperger's syndrome. European Journal of Neuroscience, 36(6), 2782-2788. doi:10.1111/j.14609568.2012.08172.x

Oner, O., Devrimci-Ozguven, H., Oktem, F., Yagmurlu, B., Baskak, B., \& Munir, K. M. (2007). Proton MR spectroscopy: Higher right anterior cingulate $\mathrm{n}$-acetylaspartate/choline ratio in Asperger syndrome compared with healthy controls. American Journal of Neuroradiology, 28(8), 1494-1498. doi: 10.3174/ajnr. a0625

Price, K. J., Edgell D., \& Kerns K. A. (2012). Timing deficits are implicated in motor dysfunction in Asperger's Syndrome. Research in Autism Spectrum Disorders, 6(2), 857-860. doi: 10.1016/j. rasd.2011.11.007

Price, K. J., Shiffrar, M. \& Kerns, K. A. (2012). Movement perception and movement production in Asperger's Syndrome. Research in Autism Spectrum Disorders, 6(1), 391-98. doi: 10.1016/j. rasd.2011.06.013

Radulescu, E., Ganeshan, B., Minati, L., Beacher, F. D. C. C., Gray, M. A., Chatwin, C., et al. (2012). Gray matter textural heterogeneity as a potential in-vivo biomarker of fine structural abnormalities in Asperger syndrome. The Pharmacogenomics Journal, 13(1), 70-79. doi: 10.1038/tpj.2012.3

Saalasti, S., Kätsyri, J., Tiippana, K., Laine-Hernandez, M., von Wendt, L., \& Sams, M. (2011). Audiovisual speech perception and eye gaze behavior of adults with Asperger syndrome. Jour- nal of Autism and Developmental Disorders, 42(8), 1606-15. doi: 10.1007/s10803-011-1400-0

Saalasti, S., Tiippana, K., Kätsyri, J., \& Sams, M. (2011). The effect of visual spatial attention on audiovisual speech perception in adults with Asperger syndrome. Experimental Brain Research, 213(2-3), 283-290. doi: 10.1007/s00221-011-2751-7

Samson, A. C., Huber, O., \& Ruch, W. (2010). Teasing, ridiculing and the relation to the fear of being laughed at in individuals with Asperger's syndrome. Journal of Autism and Developmental Disorders, 41(4), 475-83. doi: 10.1007/s10803-010-1071-2

Sato, W., Uono, S., Okada, T., \& Toichi, M. (2010). Impairment of unconscious, but not conscious, gaze-triggered attention orienting in Asperger's disorder. Research in Autism Spectrum Disorders, 4(4), 782-786. doi: 10.1016/j.rasd.2010.02.002

Saulnier, C. A., \& Klin, A. (2006). Brief report: Social and communication abilities and disabilities in higher functioning individuals with autism and Asperger syndrome. Journal of Autism and Developmental Disorders, 37(4), 788-793. doi: 10.1007/s10803006-0288-6

Sawyer, A. C. P., Williamson, P., \& Young, R. L. (2011). Can gaze avoidance explain why individuals with asperger's syndrome can't recognise emotions from facial expressions? Journal of Autism and Developmental Disorders, 42(4), 606-618. doi: 10.1007/ s10803-011-1283-0

Schultz, R. T., Romanski, L. M., \& Tsatsanis, K. D. (2000). Neurofunctional models of autistic disorder and Asperger syndrome: clues from neuroimaging. In A. Klin, F.R Volkmar \& S.S Sparrow (Eds.), Asperger syndrome (pp. 172-209.). New York: Guilford Press.

Semrud-Clikeman, M., \& Fine, J. (2011). Presence of Cysts on Magnetic Resonance Images (MRIs) in children with asperger disorder and nonverbal learning disabilities. Journal of Child Neurology, 26(4), 471-475. doi: 10.1177/0883073810384264

Semrud-Clikeman, M., Fine, J. G., Bledsoe, J., \& Zhu, D. C. (2013). Magnetic resonance imaging volumetric findings in children with Asperger syndrome, nonverbal learning disability, or healthy controls. Journal of Clinical and Experimental Neuropsychology, 35(5), 540-550. doi: 10.1080/13803395.2013.795528

Semrud-Clikeman, M., Walkowiak, J., Wilkinson, A., \& Butcher, B. (2010). Executive functioning in children with Asperger syndrome, ADHD-combined type, ADHD-predominately inattentive type, and controls. Journal of Autism and Developmental Disorders, 40(8), 1017-1027. doi: 10.1007/s10803-010-0951-9

Setoh, P., Marschik, P. B., Einspieler, C., \& Esposito, G. (2017). Autism spectrum disorder and early motor abnormalities: Connected or coincidental companions? Research in Developmental Disabilities, 60, 13-15. doi: 10.1016/j.ridd.2016.11.001

Shamay-Tsoory, S. G., Gev, E., Aharon-Peretz, J., \& Adler, N. (2010). Brain asymmetry in emotional processing in Asperger syndrome. Cognitive and Behavioral Neurology, 23(2), 74-84. doi: 10.1097/wnn.0b013e3181d748ec

Shamay-Tsoory, S. G., Lester, H., Chisin, R., Israel, O., Bar-Shalom, R., Peretz, A., et al. (2005). The neural correlates of understanding the other's distress: A positron emission tomography investigation of accurate empathy. Neuroimage, 27(2), 468-472. doi: 10.1016/j.neuroimage.2005.05.012

Shumer, D. E., Reisner, S. L., Edwards-Leeper, L., \& Tishelman, A. (2016). Evaluation of Asperger syndrome in youth present- 
ing to a gender dysphoria clinic. LGBT Health, 3(5), 387-390. doi: 10.1089/lgbt.2015.0070

Siaperas, P., Ring, H. A., McAllister, C. J., Henderson, S., Barnett, A., Watson, P., et al. (2011). Atypical movement performance and sensory integration in Asperger's syndrome. Journal of Autism and Developmental Disorders, 42(5), 718-725. doi: 10.1007/ s10803-011-1301-2

Smucker, D. (2011). The role of the right hemisphere in processing sarcasm in Asperger's disorder [MSc. Thesis]. Muncie: Ball State University.

Spek, A. A., Scholte, E. M., \& Van Berckelaer-Onnes, I. A. (2007). Brief report: The use of WAIS-III in adults with HFA and Asperger syndrome. Journal of Autism and Developmental Disorders, 38(4), 782-787. doi: 10.1007/s10803-007-0446-5

Sucksmith, E., Allison, C., Baron-Cohen, S., Chakrabarti, B., \& Hoekstra, R. A. (2013). Empathy and emotion recognition in people with autism, first-degree relatives, and controls. Neuropsychologia, 51(1), 98-105. doi: 10.1016/j.neuropsychologia.2012.11.013

Sugihara, G., Y. Ouchi, K. Nakamura, Y. Sekine \& Mori, N (2007). [Advances in neuroimaging research on Asperger syndrome (Japanese)]. Nihon Rinsho, 65(3), 449-452. PMID: 17354556

Tanguay, P. E., Robertson, J., \& Derrick, A. (1998). A dimensional classification of autism spectrum disorder by social communication domains. Journal of the American Academy of Child \& Adolescent Psychiatry, 37(3), 271-277. doi: 10.1097/00004583199803000-00011

Tantam, D., \& Girgis, S. (2008). Recognition and treatment of Asperger syndrome in the community. British Medical Bulletin, 89(1), 41-62. doi: 10.1093/bmb/ldp006

Tanweer, T., Rathbone, C. J., \& Souchay, C. (2010). Autobiographical memory, autonoetic consciousness, and identity in Asperger syndrome. Neuropsychologia, 48(4), 900-908. doi: 10.1016/j.neuropsychologia.2009.11.007

Tsai, A. C., Savostyanov, A. N., Wu, A., Evans, J. P., Chien, V. S., Yang, H. H., et al. (2013). Recognizing syntactic errors in Chinese and English sentences: Brain electrical activity in Asperger's syndrome. Research in Autism Spectrum Disorders, 7(7), 889-905. doi: $10.1016 /$ j.rasd.2013.02.001

Uono, S., Sato, W., \& Toichi, M. (2009). Dynamic fearful gaze does not enhance attention orienting in individuals with Asperger's disorder. Brain and Cognition, 71(3), 229-233. doi: 10.1016/j. bandc.2009.08.015

Vannucchi, G., Masi, G., Toni, C., Dell'Osso, L., Erfurth, A., \& Perugi, G. (2014). Bipolar disorder in adults with Asperger's Syndrome: A systematic review. Journal of Affective Disorders, 168, 151-160. doi: 10.1016/j.jad.2014.06.042

Watanabe, K., Ikeda, H., \& Miyao, M. (2010). Learning efficacy of explicit visuomotor sequences in children with attentiondeficit/hyperactivity disorder and Asperger syndrome. Experimental Brain Research, 203(1), 233-239. doi: 10.1007/s00221-0102217-3

Weimer, A. A., Parault Dowds, S. J., Fabricius, W. V., Schwanenflugel, P. J., \& Suh, G. W. (2017). Development of constructivist theory of mind from middle childhood to early adulthood and its relation to social cognition and behavior. Journal of Experimental Child Psychology, 154, 28-45. doi: 10.1016/j.jecp.2016.10.002
Welchew, D. E., Ashwin, C., Berkouk, K., Salvador, R., Suckling, J., Baron-Cohen, S., \& Bullmore, E. (2005). Functional disconnectivity of the medial temporal lobe in Asperger's syndrome. Biological Psychiatry, 57(9), 991-998. doi: 10.1016/j.biopsych.2005.01.028

Wong, N., Beidel, D. C., Sarver, D. E., \& Sims, V. (2012). Facial emotion recognition in children with high functioning autism and children with social phobia. Child Psychiatry \& Human Development, 43(5), 775-794. doi: 10.1007/s10578-012-0296-Z 
